\title{
Flooding tendencies for the city of Ensenada, Baja, California, Mexico, 1948-2004
}

\author{
J. Soares ${ }^{1}$, R. Blanco ${ }^{2}$, C. García $^{3}$, E. Inzunza ${ }^{1} \&$ P. Rousseau ${ }^{1}$ \\ ${ }^{1}$ Faculty of Engineering, \\ Autonomous University of Baja California UABC in Ensenada, Mexico \\ ${ }^{2}$ Oceanologic Research Institute IIO of the Autonomous University of \\ Baja California UABC in Ensenada, Mexico \\ ${ }^{3}$ Independent Researcher
}

\begin{abstract}
Precipitation data collected from 4 stations located in the city of Ensenada, Baja California Mexico from 1948 to 2004 were analyzed and associated with damaging floods. Precipitation values from 1948 to 1977 did not exceed $35 \mathrm{~mm}$. in 24 hours; however, rainfall daily reports of 51,52 and $81 \mathrm{~mm}$. were found in 1978, 1979 and 1980, respectively, exceeding the 50mm. of water/day capacity of the sewage system for the city causing considerable infrastructure damage and even the loss of lives. No values greater than $46 \mathrm{~mm}$ have been observed from 1981 to 2004 yet landslides have been frequently observed in areas with steep slopes and alluvial material in some parts of the city. Floodplain occupancy, lack of maintenance of drainage systems as well as inundations in low land areas, account for the main flooding problems for the city. A map is developed in this study showing the different flooding zones associated with the amount of precipitation for the city. Remedial options are offered for city planners
\end{abstract}

Keywords: damaging flood, drainage systems, landslides, anthropogenic impact.

\section{Introduction}

Archived rainfall data for the city of Ensenada, Baja California in Mexico is relatively recent (1948- ) compared with stored rainfall data for our neighbouring San Diego, California (1850- ), in the United States. Although Ensenada is located approximately $120 \mathrm{~km}$ south of the border with the U.S.A., there has not been a study that relates the amount of water precipitation in the city of San 
Diego, to quantities for Ensenada which could lead to some developments in adequate weather prediction, timely flood-warning systems and management plans to prevent or reduce flooding effects that act upon the wellbeing of the community. This paper is the first of its kind and is built upon a short history of observed damaging flooding for our city to improve the understanding of the water flow behaviour as housing development increases.

In general, the study area includes zones with smooth surface features constituted by alluvial deposits of gravel, sands and clay, while higher areas are composed mainly by granitic rocks. The majority of the population is located on the alluvial soils that derive from erosion of the surrounding hills, as well as deposits from streams. Quaternary lacustrine and marshy soils occupy zones closer to the ocean. The average temperature for the city is approximately $18.1^{\circ} \mathrm{C}[1]$ and drought periods are present for the most part of the year so no infrastructure for collecting rain has been set up.

The municipal sewage system was built to hold a maximum of $50 \mathrm{~mm}$ of rain/day and precipitation values that surpass this limit are causing considerable damage to the city's infrastructure; apart from this, sewage is filled with trash falling from the sewer drain and sediment that has been transported along with the rain reducing the $50 \mathrm{~mm}$ and flooding important parts of the city (Figure 1).

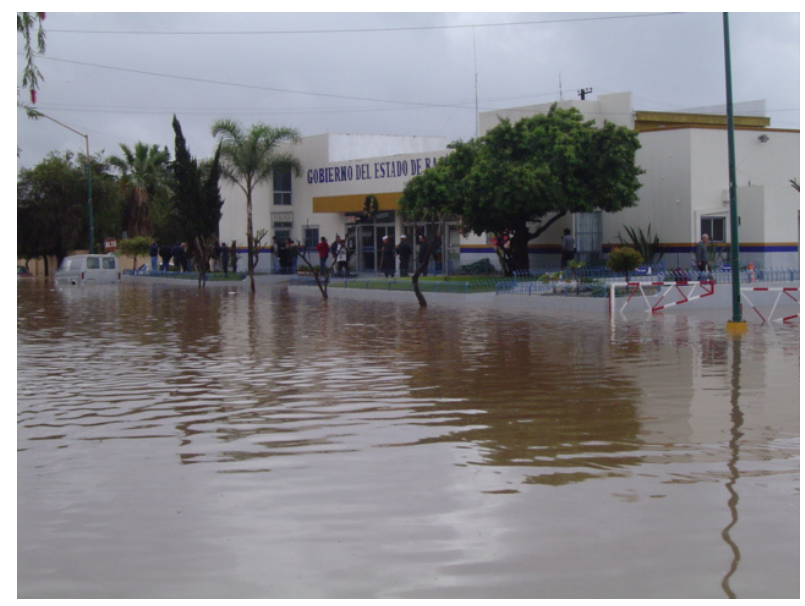

Figure 1: Flooding of ISSTECALI Hospital in 1978 due to saturation of the sewage system.

In 1995 a Land Use Chart was produced by city planners projecting housing developments towards the NE part of the city, where granitic rock composes the terrain; county government change resulted in housing development towards the south of the city, invading regions for sowing where land had been cultivated for more than 20 years in the stream plains.

Seismic velocity profiles were made in 1997 [2] showing more than $30 \mathrm{~m}$ of layer thickness for the alluvial deposits to the South of Ensenada whereas in the 
northern part of the city known as the Downtown Area, thickness of the alluvial bed is approximately $5 \mathrm{~m}$.

Figure 2a shows the Downtown Area of Ensenada, before land was reclaimed from the sea and occupied with tourist leisure activities and Port operations. The Downtown Area was filled with sand and alluvial deposits below sea level. When abundant rain is present the Downtown Area inevitably floods and traffic jams are unavoidable. Borehole results obtained in 1993 by the "Laboratorio de Materiales" [3] (Figure 2b) showed freatic water levels at a depth of $1.10 \mathrm{~m}$. This level is influenced by tidal changes as it is very close to the ocean.
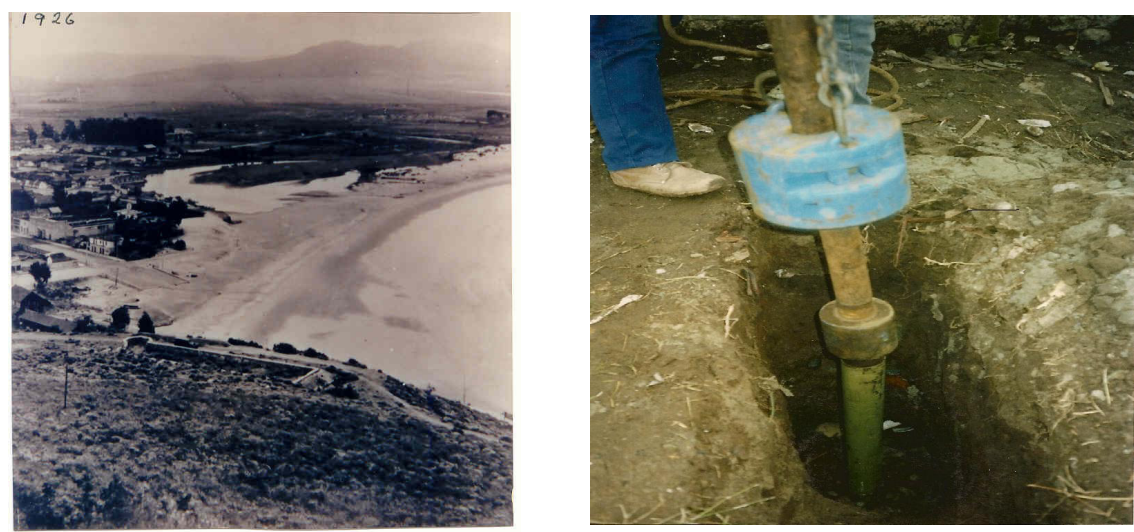

Figure 2: a) Ensenada in 1926 before land was reclaimed from the sea. b) Borehole drilling in the Downtown Area.

\section{Data analyses and interpretation}

Data precipitation records from four local meteorological stations over a period from 1948 to 2004 were analyzed. From the four stations chosen, the data from station Punta Banda showed extremely gappy records probably due to a poor maintenance program; data from this station proved useless for the analysis and was discarded, allowing us to use data from 3 stations only: La Presa (ELP) located at coordinates N31 $53^{\prime} 45^{\prime \prime}, 116^{\circ} 35^{\prime} 47^{\prime \prime} \mathrm{W}$, El Ciprés (ECP) at $\mathrm{N}$ $31^{\circ} 47^{\prime} 48^{\prime \prime}, 116^{\circ} 35^{\prime} 37^{\prime \prime} \mathrm{W}$, and San Carlos (ESC) at N 31 ${ }^{\circ} 47^{\prime} 03^{\prime \prime}, 116^{\circ} 27^{\prime} 00^{\prime \prime} \mathrm{W}$. An initial visual inspection of the time series for the three remainder stations showed that they have different record lengths: ELP station runs from 1948 to 2004, while ECP station has data from 1976 to 2004; ESC station started to record data from 1962 up to 2004. For the purpose of this work, time series were cut to match the same length (1976-2004) to allow fair time comparisons between them. Tables 1, 2 and 3 only show data for the months for the rainy season considering that no significant rainfall values are seen during the summer (dry season). 
Table 1: $\quad$ Monthly accumulated precipitation (Map) in [mm] for El Ciprés (ECP) Weather Station, for the rainy season period. $M$ is used as a symbol representing the months and $\boldsymbol{\Delta}$ is used when no data was available.

\begin{tabular}{|c|c|c|c|c|c|c|c|c|c|c|c|c|c|c|}
\hline year & $\mathrm{M}$ & $\begin{array}{l}\mathrm{MaP} \\
{[\mathrm{mm}]}\end{array}$ & $\mathrm{M}$ & $\begin{array}{l}\mathrm{MaP} \\
{[\mathrm{mm}]}\end{array}$ & $\mathrm{M}$ & $\begin{array}{l}\mathrm{MaP} \\
{[\mathrm{mm}]}\end{array}$ & $\mathrm{M}$ & $\begin{array}{l}\mathrm{MaP} \\
{[\mathrm{mm}]}\end{array}$ & $\mathrm{M}$ & $\begin{array}{l}\mathrm{MaP} \\
{[\mathrm{mm}]}\end{array}$ & $\mathrm{M}$ & $\begin{array}{l}\mathrm{MaP} \\
{[\mathrm{mm}]}\end{array}$ & $\mathrm{M}$ & $\begin{array}{l}\mathrm{MaP} \\
{[\mathrm{mm}]}\end{array}$ \\
\hline 1969 & Jan & $\bar{\Delta}$ & Feb & $\bar{\Delta}$ & Mar & $\bar{\Delta}$ & Apr & $\boldsymbol{\Delta}$ & Oct & $\boldsymbol{\Delta}$ & Nov & $\boldsymbol{\Delta}$ & Dec & $\boldsymbol{\Delta}$ \\
\hline 1978 & $\sqrt{ }$ & 113 & $\sqrt{ }$ & 112 & $\sqrt{ }$ & 124 & $\sqrt{ }$ & $\boldsymbol{\Delta}$ & $\sqrt{ }$ & $\boldsymbol{\Delta}$ & $\sqrt{ }$ & $\boldsymbol{\Delta}$ & $\sqrt{ }$ & $\boldsymbol{\Delta}$ \\
\hline 1979 & $\sqrt{ }$ & 109 & $\sqrt{ }$ & $\bar{\Delta}$ & $\sqrt{ }$ & $\Delta$ & $\sqrt{ }$ & $\boldsymbol{\Delta}$ & $\sqrt{ }$ & $\boldsymbol{\Delta}$ & $\sqrt{ }$ & $\boldsymbol{\Delta}$ & $\sqrt{ }$ & $\boldsymbol{\Delta}$ \\
\hline 1980 & $\sqrt{ }$ & 133 & $\sqrt{ }$ & 120 & $\sqrt{ }$ & $\bar{\Delta}$ & $\sqrt{ }$ & $\Delta$ & $\sqrt{ }$ & $\Delta$ & $\sqrt{ }$ & $\Delta$ & $\sqrt{ }$ & $\Delta$ \\
\hline 1993 & $\sqrt{ }$ & 117 & $\sqrt{ }$ & $\Delta$ & $\sqrt{ }$ & $\Delta$ & $\sqrt{ }$ & $\Delta$ & $\sqrt{ }$ & $\Delta$ & $\sqrt{ }$ & $\Delta$ & $\sqrt{ }$ & $\Delta$ \\
\hline 1995 & $\sqrt{ }$ & $\boldsymbol{\Delta}$ & $\sqrt{ }$ & $\Delta$ & $\sqrt{ }$ & $\Delta$ & $\sqrt{ }$ & $\boldsymbol{\Delta}$ & $\sqrt{ }$ & $\mathbf{\Delta}$ & $\sqrt{ }$ & 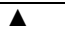 & $\sqrt{ }$ & $\mathbf{\Delta}$ \\
\hline 1998 & $\sqrt{ }$ & 52 & $\sqrt{ }$ & 217 & $\sqrt{ }$ & 79.7 & $\sqrt{ }$ & $\Delta$ & $\sqrt{ }$ & $\Delta$ & $\sqrt{ }$ & $\Delta$ & $\sqrt{ }$ & $\Delta$ \\
\hline
\end{tabular}

Table 2: Monthly accumulated precipitation (Map) in [mm] for SanCarlos(ESC) Weather Station, for the rainy season period. $M$ is used as a symbol representing the months and $\boldsymbol{\Delta}$ is used when no data was available.

\begin{tabular}{|l|l|l|l|l|l|l|l|l|l|l|l|l|l|l|}
\hline year & $\mathrm{M}$ & $\begin{array}{l}\mathrm{MaP} \\
{[\mathrm{mm}]}\end{array}$ & $\mathrm{M}$ & $\begin{array}{l}\mathrm{MaP} \\
{[\mathrm{mm}]}\end{array}$ & $\mathrm{M}$ & $\begin{array}{l}\mathrm{MaP} \\
{[\mathrm{mm}]}\end{array}$ & $\mathrm{M}$ & $\begin{array}{l}\mathrm{MaP} \\
{[\mathrm{mm}]}\end{array}$ & $\mathrm{M}$ & $\begin{array}{l}\mathrm{MaP} \\
{[\mathrm{mm}]}\end{array}$ & $\mathrm{M}$ & $\begin{array}{l}\mathrm{MaP} \\
{[\mathrm{mm}]}\end{array}$ & $\begin{array}{l}\mathrm{M} \\
{[\mathrm{mm}]}\end{array}$ \\
\hline 1969 & Jan & 171 & Feb & 115 & $\mathrm{Mar}$ & $\boldsymbol{\Delta}$ & $\mathrm{Apr}$ & $\boldsymbol{\Delta}$ & $\mathrm{Oct}$ & $\boldsymbol{\Delta}$ & Nov & $\boldsymbol{\Delta}$ & Dec & $\boldsymbol{\Delta}$ \\
\hline 1978 & $\sqrt{ }$ & 202 & $\sqrt{ }$ & 157 & $\sqrt{ }$ & 169 & $\sqrt{ }$ & $\boldsymbol{\Delta}$ & $\sqrt{ }$ & 114 & $\sqrt{ }$ & $\boldsymbol{\Delta}$ & $\sqrt{ }$ & 95 \\
\hline 1979 & $\sqrt{ }$ & 157.4 & $\sqrt{ }$ & $\boldsymbol{\Delta}$ & $\sqrt{ }$ & 138 & $\sqrt{ }$ & $\boldsymbol{\Delta}$ & $\sqrt{ }$ & $\boldsymbol{\Delta}$ & $\sqrt{ }$ & $\boldsymbol{\Delta}$ & $\sqrt{ }$ & 89 \\
\hline 1980 & $\sqrt{ }$ & 219 & $\sqrt{ }$ & 211 & $\sqrt{ }$ & 117 & $\sqrt{ }$ & $\boldsymbol{\Delta}$ & $\sqrt{ }$ & $\boldsymbol{\Delta}$ & $\sqrt{ }$ & $\boldsymbol{\Delta}$ & $\sqrt{ }$ & $\boldsymbol{\Delta}$ \\
\hline 1993 & $\sqrt{ }$ & 329 & $\sqrt{ }$ & 185 & $\sqrt{ }$ & 245 & $\sqrt{ }$ & $\boldsymbol{\Delta}$ & $\sqrt{ }$ & $\boldsymbol{\Delta}$ & $\sqrt{ }$ & $\boldsymbol{\Delta}$ & $\sqrt{ }$ & $\boldsymbol{\Delta}$ \\
\hline 1995 & $\sqrt{ }$ & 147 & $\sqrt{ }$ & $\boldsymbol{\Delta}$ & $\sqrt{ }$ & 121 & $\sqrt{ }$ & $\boldsymbol{\Delta}$ & $\sqrt{ }$ & $\boldsymbol{\Delta}$ & $\sqrt{ }$ & $\boldsymbol{\Delta}$ & $\sqrt{ }$ & $\boldsymbol{\Delta}$ \\
\hline 1998 & $\sqrt{ }$ & $\boldsymbol{\Delta}$ & $\sqrt{ }$ & $\mathbf{3 7 4}$ & $\sqrt{ }$ & $\boldsymbol{\Delta}$ & $\sqrt{ }$ & $\boldsymbol{\Delta}$ & $\sqrt{ }$ & $\boldsymbol{\Delta}$ & $\sqrt{ }$ & $\boldsymbol{\Delta}$ & $\sqrt{ }$ & $\boldsymbol{\Delta}$ \\
\hline
\end{tabular}

Table 3: $\quad$ Monthly accumulated precipitation (Map) in [mm] for La Presa (ELP) Weather Station, for the rainy season period. $M$ is used as a symbol representing the months and $\boldsymbol{\Delta}$ is used when no data was available.

\begin{tabular}{|c|c|c|c|c|c|c|c|c|c|c|c|c|c|c|}
\hline year & $\mathrm{M}$ & $\begin{array}{l}\mathrm{MaP} \\
{[\mathrm{mm}]}\end{array}$ & $\mathrm{M}$ & $\begin{array}{l}\mathrm{MaP} \\
{[\mathrm{mm}]}\end{array}$ & $\mathrm{M}$ & $\begin{array}{l}\mathrm{MaP} \\
{[\mathrm{mm}]}\end{array}$ & $\mathrm{M}$ & $\begin{array}{l}\mathrm{MaP} \\
{[\mathrm{mm}]}\end{array}$ & $\mathrm{M}$ & $\begin{array}{l}\mathrm{MaP} \\
{[\mathrm{mm}]}\end{array}$ & $\mathrm{M}$ & $\begin{array}{l}\mathrm{MaP} \\
{[\mathrm{mm}]}\end{array}$ & $\mathrm{M}$ & $\begin{array}{l}\mathrm{MaP} \\
{[\mathrm{mm}]}\end{array}$ \\
\hline 1969 & Jan & 108 & Feb & 99 & Mar & $\Delta$ & Apr & $\boldsymbol{\Delta}$ & Oct & $\boldsymbol{\Delta}$ & Nov & $\boldsymbol{\Delta}$ & Dec & $\Delta$ \\
\hline 1978 & $\sqrt{ }$ & 159 & $\sqrt{ }$ & 148 & $\sqrt{ }$ & 165 & $\sqrt{ }$ & $\boldsymbol{\Delta}$ & $\sqrt{ }$ & $\boldsymbol{\Delta}$ & $\sqrt{ }$ & $\boldsymbol{\Delta}$ & $\sqrt{ }$ & 86 \\
\hline 1979 & $\sqrt{ }$ & 118 & $\sqrt{ }$ & $\Delta$ & $\sqrt{ }$ & 126 & $\sqrt{ }$ & $\Delta$ & $\sqrt{ }$ & $\Delta$ & $\sqrt{ }$ & $\Delta$ & $\sqrt{ }$ & $\mathbf{\Delta}$ \\
\hline 1980 & $\sqrt{ }$ & 186 & $\sqrt{ }$ & 184 & $\sqrt{ }$ & $\boldsymbol{\Delta}$ & $\sqrt{ }$ & $\boldsymbol{\Delta}$ & $\sqrt{ }$ & $\mathbf{\Delta}$ & $\sqrt{ }$ & $\boldsymbol{\Delta}$ & $\sqrt{ }$ & $\Delta$ \\
\hline 1993 & $\sqrt{ }$ & 217 & $\sqrt{ }$ & $\Delta$ & $\sqrt{ }$ & $\Delta$ & $\sqrt{ }$ & $\boldsymbol{\Delta}$ & $\sqrt{ }$ & $\boldsymbol{\Delta}$ & $\sqrt{ }$ & $\boldsymbol{\Delta}$ & $\sqrt{ }$ & $\Delta$ \\
\hline 1995 & $\sqrt{ }$ & 135 & $\sqrt{ }$ & 124 & $\sqrt{ }$ & $\Delta$ & $\sqrt{ }$ & $\boldsymbol{\Delta}$ & $\sqrt{ }$ & $\boldsymbol{\Delta}$ & $\sqrt{ }$ & $\boldsymbol{\Delta}$ & $\sqrt{ }$ & $\Delta$ \\
\hline 1998 & $\sqrt{ }$ & $\Delta$ & $\sqrt{ }$ & 237 & $\sqrt{ }$ & 93 & $\sqrt{ }$ & $\boldsymbol{\Delta}$ & $\sqrt{ }$ & $\Delta$ & $\sqrt{ }$ & $\boldsymbol{\Delta}$ & $\sqrt{ }$ & $\Delta$ \\
\hline
\end{tabular}




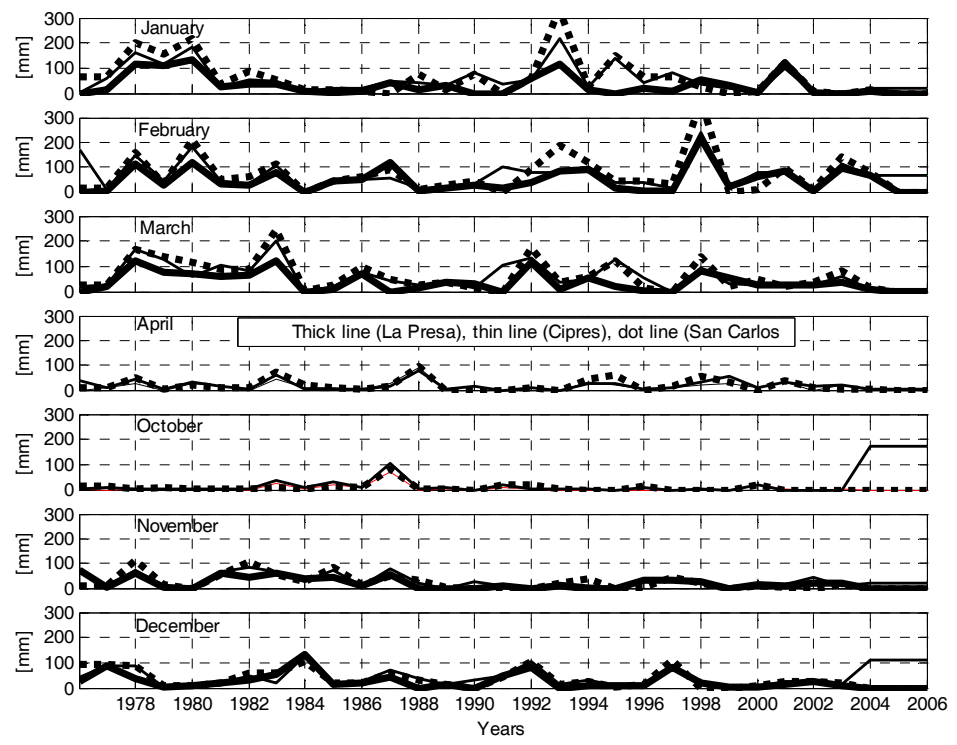

Figure 3: Overlapped total precipitation/year data for the three Stations used in this study.

Overlapped data for the three stations were graphed for a clearer comparison and are shown in Figure 3. Mainly January, February and March are known for the arrival of storms from the NW.

It is observed that important rainfall peaks differ in amplitude between the three stations but show a good agreement in time; major rainfall amplitudes $(>300 \mathrm{~mm})$ are registered at ESC, which is located to the SE of the city where construction companies are building housing developments while ELP station (with $>200 \mathrm{~mm}$ of rainfall as its maximum value) is located to the north of Ensenada, at the López Zamora Dam where city planners in 1995 projected the housing developments. ECP station showed the lowest values of the group (less than 200mm). Data shows other precipitation peaks, although minor, occurring in April, suggesting the presence of occasional out-of-season showers. In early November, rainfall starts to exhibit increasing values, suggesting the prelude of the rainy season.

The most relevant rainfall peaks occur in the years 1978-1980 and 1993. Comparisons between stations clearly show that February is the most important month in terms of accumulated precipitation, followed by the month of January.

To find which part of the city receives the most amount of water during the rainy season we estimated the correlation coefficients (cc) between the stations. For stations ECP and ELP, $\mathrm{cc}=0.77$; for $\mathrm{ECP}$ and $\mathrm{ESC}, \mathrm{cc}=0.76$ and between ECS and ELP $c c=0.94$. These numbers indicate that the city receives approximately the same amount of rainfall in the northern sector than in the 
southern sector. Similar strategies to manage the excess of rainfall along the city must be applied in the event of the presence of a severe storm.

Slope analysis using a digital elevation model with a $30 \times 30 \mathrm{~m}$ grid [4] along with field corroborations was done to properly denote flooding areas and their main causes as a first attempt for preparing a zoning of the city.

Fieldwork gave a good basis for classifying the main factors contributing to the flooding problems:

a) Inadequate drainage systems.- Massive housing expansion towards the south of the city are built over stream plains (Figures 4a), 4b)) and the major construction companies did not consider a rain sewer system, leaving the domestic drainage system as the sole means of conducing the rain; this system is already filled with waste and sediments and eventually leads to overflowing out of the gutters to the streets wasting the much needed rain water.
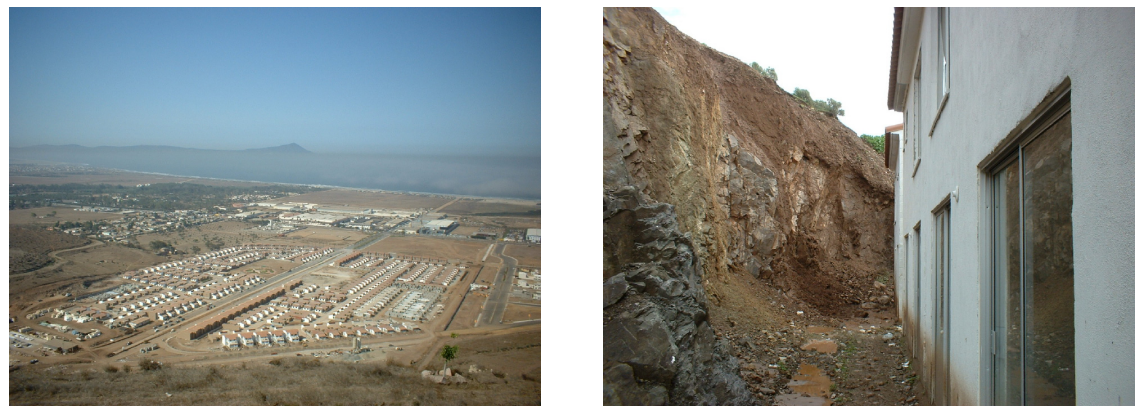

Figure 4: a) Major Housing Development to the South of Ensenada built over a Stream Plain. b) Anthropogenic impact inducing flooding as incorrect deviation of runoff water concentrated from developed areas saturates the soil.
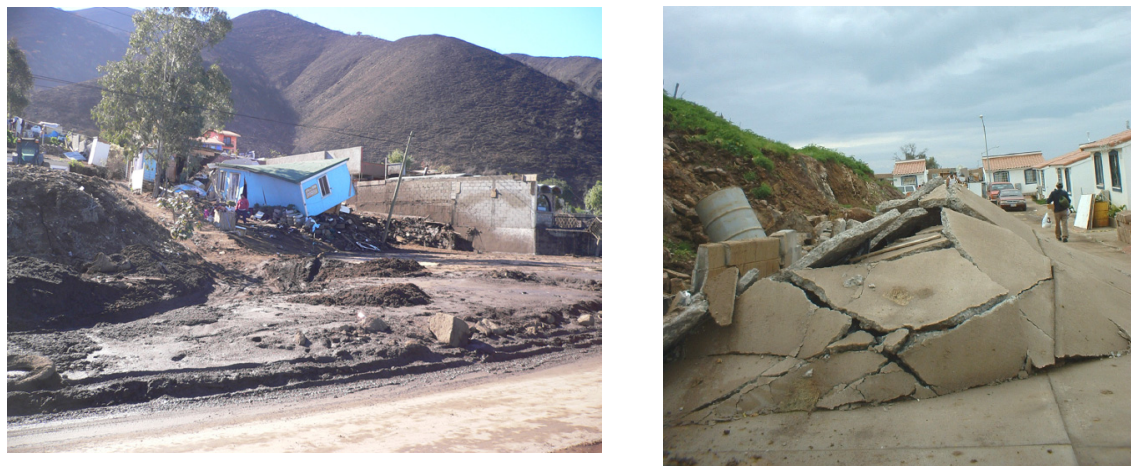

Figure 5: a) Landslide in the SW of Ensenada where hills are unprotected by recent wildfires. b) Saturation of the Soil in a Housing Complex south of the city where sowing was the major activity before the county government changed the use of the soil. 


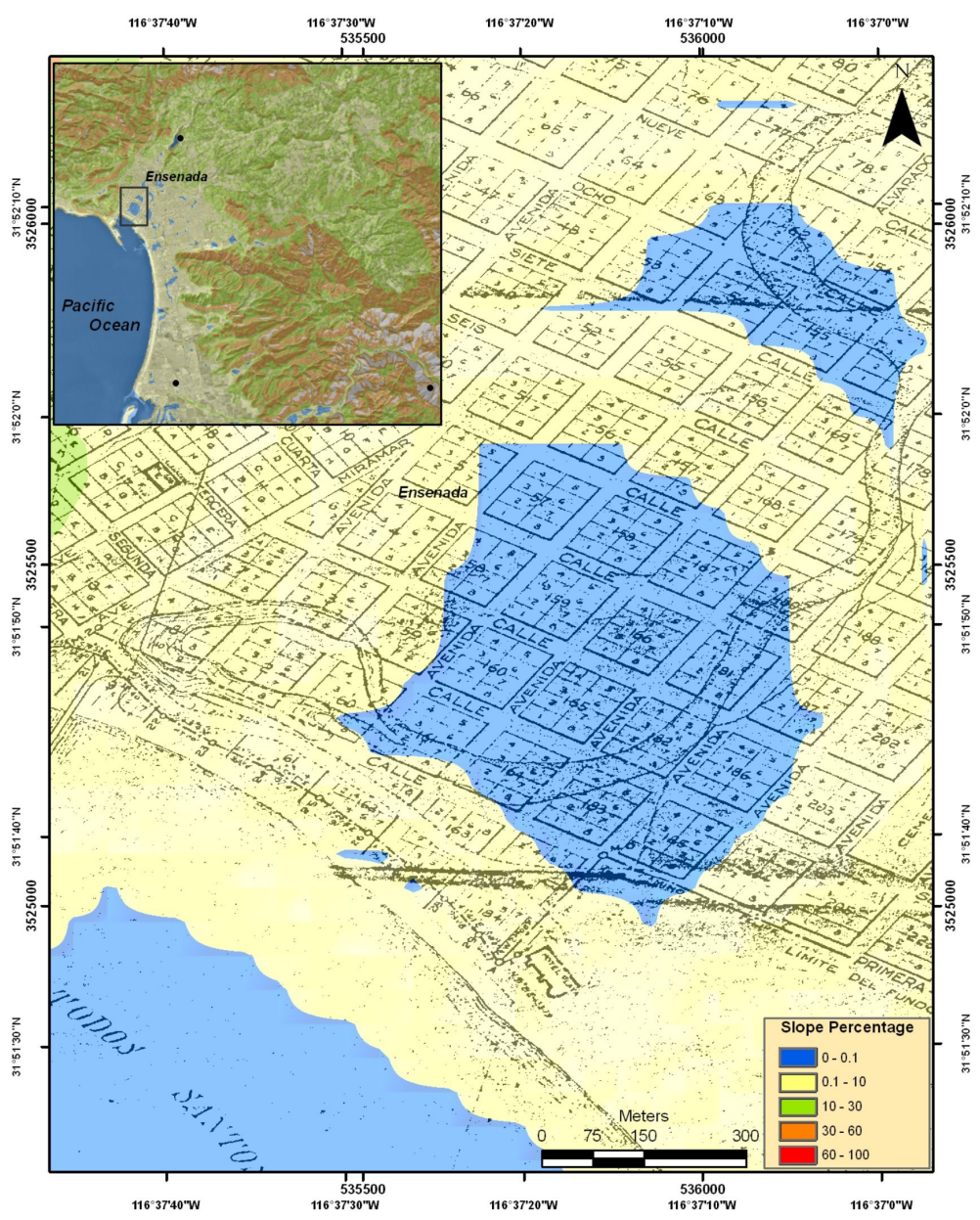

Figure 6: Map showing flooding zones for the Downtown Area of Ensenada. Far left: Black dots indicate the location of the Weather Stations used in this study.

b) Landslides- Landslides are generated by two major factors: Loss of vegetation and water saturation. Loss of vegetation is caused by wildfires induced by hot Santa Ana Winds occurring in late fall resulting in destabilization of surface soil and an increase in the velocity of surface water runoff causing mudflows in lower areas where clays form the hill areas (Figure 5a)). South of the city, landslides occur due to water saturation of the soil for the housing developments built over stream plains (Figure 5b))

c) Terrain Morphology- The city has 3 main streams: El Gallo, Ensenada and El Campillo. Although deviated by population growth, traces of their original routes remain in the form of small watersheds along the main streets, converting 
into ponds when it rains where cars can get stuck. Since the year 2000, great effort has been done by city managers in covering the streets with concrete pavement, but the original drainage system has not been updated to fit the requirements of an increasing population resulting in water running over the pavement raising the flow and volume which worsens the flooding. Currently the city is building 3 bridges across the Ensenada Stream in 3 of the main streets in the Downtown Area to release traffic jams when it rains.

A map was developed for this study, showing the slope percentages for the city (Figure 6). Regions below sea level and with slope percentages of $0-0.1$ are considered susceptible to flooding.

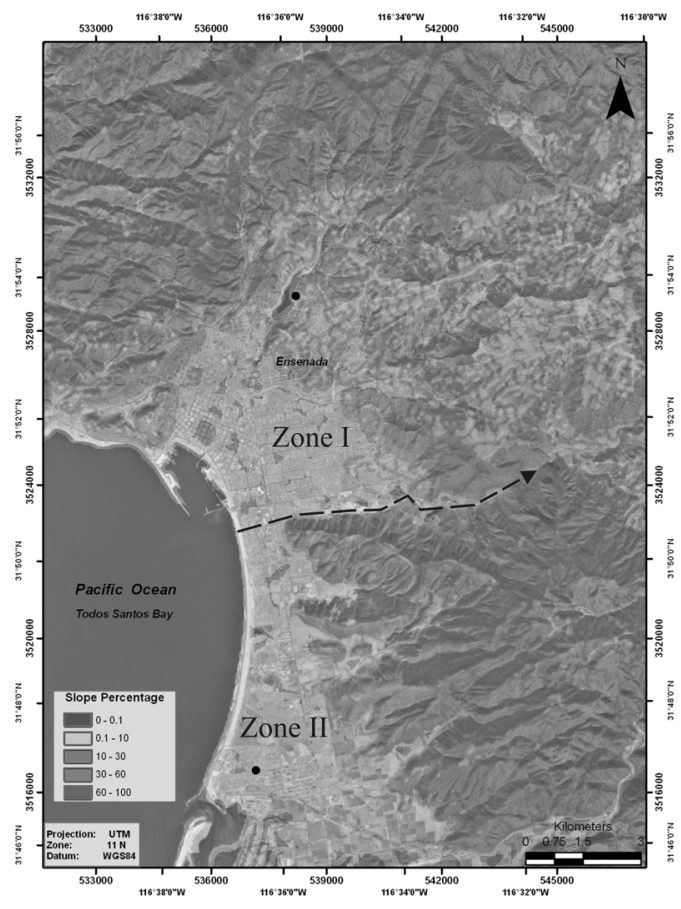

Figure 7: Macrozonation for the city of Ensenada according to the main flooding causes. The arrow points to the site where Arroyo El Gallo is originated.

Considering all the factors that contribute to the flooding of Ensenada, we decided to make a macrozonation for the city, as a first attempt to characterize the major problems that afflict the region. Figure 7 shows the consensus division made by the authors in this study. Zone I flooding occurs mainly because of the problems arising by the land reclaimed from the sea which is below sea level. Zone II flooding occurs mainly because the soil is not fitted for large housing development and deviation of the stream channel into smaller dug passages with 
no concrete for bottom lining and slope revetment. Both Zones have inadequate drainage systems.

\section{Conclusions and recommendations}

Due to its hydro-climatic and geologic characteristics, Ensenada produces large quantities of sediment deposits. Based on observations, it is imminent to execute Works to trap the sediments at the sub-basin level and to increase the maintenance of the drainage system. Continuous maintenance programs must begin in the month of October and continue to April, as those are the months expected to have the heaviest rainfalls. As it is financially possible for the city, it is imperative to change the drainage system to a larger one that serves the population necessities. At all costs, city planners should avoid housing developments over areas of stream plains. It is also important to assemble a separate system for collecting rain in Zone 2. Although its topography is more uneven, similar actions have been proposed for Tijuana, a city located $100 \mathrm{~km}$. North of Ensenada by the Subdirector of the State Commission for the Public Services of Tijuana (CESPT) [4] who states that the one of the main problem of the drainage system is the garbage blocking the system. No action has been taken by city planners.

Reforestation in higher areas affected by wildfires is also recommended.

\section{References}

[1] Portal Ciudadano de Baja California, México. Ensenada. http://www.bajacalifornia.gob.mx/portal/nuestro_estado/municipios/ensenad a/clima.jsp

[2] Soares J. (2003) Aplicación de la microzonación sísmica a la vulnerabilidad de estructuras críticas en la ciudad de Ensenada, B. C. Tesis de Maestría. Centro de Investigación Científica y de Educación Superior de Ensenada.

[3] Laboratorio de Materiales.(1993). Estudio de Mecánica de Suelos, Sección Primera. Ensenada, Baja California. Reporte Técnico para Ginsa Construcciones, S.A. de C.V.

[4] San Luis Adolfo Noticias Frontera.info. Es insuficiente el drenaje pluvial. Retrieved June 10, 2009 from http://www.arq.com.mx/noticias/Cached Pages $/ 3186 . \mathrm{html}$ 